\title{
Influence of NK Cells during Epithelial to Mesenchymal Transition in Oral cancer
}

Authors

\section{Priyashi Rao ${ }^{1}$, Birva Raiya ${ }^{2}$, Hemangini Vora ${ }^{3}$}

${ }^{1}$ MSc. Student, ${ }^{2}$ Research Assistant, ${ }^{3}$ Associate Professor

${ }^{1}$ Department of Biochemistry and Biotechnology, St. Xavier's College (Autonomous), Ahmadabad

${ }^{2,3}$ Cancer Biology Department, the Gujarat Cancer Research Institute, Ahmadabad, Gujarat, India Email: ${ }^{1}$ priyashirao183@gmail.com, ${ }^{2}$ birvab@gmail.com, ${ }^{3}$ ihcgcri@hotmail.com

\begin{abstract}
Oral carcinogenesis is a major health problem in the world. Over $90 \%$ of all Oral Cancer is classified as Oral Squamous Cell Carcinoma with loco regional relapse and cervical lymph node metastasis. Considering epithelial malignancies, the role of immune system in governing Epithelial to Mesenchymal Transition (EMT) has not been much investigated in oral cancer. The present investigation suggests a possible role of NK cells during EMT and its correlation to invasive properties of tumour. Athough a direct correlation couldn't be established but the influence of NK cells on EMT could be seen which open up new horizon for immunotherapeutic strategies in the coming years.
\end{abstract}

Keywords: NK cells, invasion, Oral squamous cell carcinoma (OSCC), EMT, E-cadherin, Vimentin.

\section{Introduction}

NK cells are cells of the innate immune system that display cytotoxic activity against an extensive range of tumor cells and tend to mark a response against process of carcinogenesis ${ }^{(1)}$. In humans, there is a correlation between low NK cell cytotoxicity in peripheral blood and increased risk of cancer ${ }^{(2)}$. Conversely, NK cell infiltration into tumor tissue is associated with better patient prognosis in multiple malignancies ${ }^{(3)}$. Epithelial to Mesenchymal Transition (EMT) a hallmark of invasion, is a biological phenomenon that allows a polarized epithelial cell to undergo biochemical changes to attain a mesenchymal cell phenotype ${ }^{(4)}$ that is often characterised by the loss of E-cadherin and gain of Vimentin expression ${ }^{(5-8)}$. Given the extensive molecular and cellular changes that occur during
EMT, it is likely that tumor cell interactions with both innate and adaptive immune cells in the tumor microenvironment will be altered ${ }^{(9)}$. Work by Lehembre et al. in $2008^{(10)}$ reveals that the Neural cell adhesion molecule (NCAM) has a role in initiating E-cadherin loss during EMT.

However, studies investigating the role of NK cells in tumor progression and metastasis are very limited. Therefore, it becomes important to understand NK cell responses in circulation as well as in tumor microenvironment, for better understanding of its role in initiating EMT in Oral carcinogenesis.

Aim of the study was to investigate the role of Peripheral blood NK Cells using Flow cytometry and Tumor infiltrating NK cells along with Ecadherin (an epithelial marker) and Vimentin (a mesenchymal marker) using Immunohistochemistry in OSCC. 


\section{Materials and Methods}

In this prospective study, NK cells were evaluated in circulation as well as in tumour tissue front of 30 Male Oral cancer patients (Buccal mucosa). Peripheral blood NK cells were also compared with those of 10 age-matched healthy controls. These patients were diagnosed and treated at The Gujarat Cancer and Research Institute within the period of November 2017-June 2018. None of the patients received any form of neo-adjuvant therapy and no patient suffered recurrence uptil the follow-up period of 8 months.

Immunophenotyping of peripheral blood NK cells, was performed by Flow cytometer BD FACS Canto TM II, (7 colour set up beads system) obtained from BD Biosciences (San Jose, USA) using a combination of monoclonal antibodies CD45 (PerCP, clone 2D1) to identify the expression of lymphocytes, CD3 (APC H-7, clone SK7) for T cells, CD56 (PE, clone MY31) for NK cells. For NK cells detection, antibodies were added to the peripheral blood $(100 \mu \mathrm{l})$ sample and incubated for 15 minutes. After incubation, $2 \mathrm{ml}$ of erythrocyte lysing solution (1:10 dilution with double distilled water) was added and incubated for 15 minutes at room temperature. Then cells were centrifuged at $400 \mathrm{~g}$ for 5 minutes and supernatant was discarded. Remaining pellet was washed twice with $2 \mathrm{ml}$ PBS and then resuspended in $500 \mu \mathrm{l}$ of PBS. Total 30,000 Lymphocytes were acquired (Figure 1).

Immunohistochemical localization of Tumor infiltrating NK cells and expression of E-cadherin and Vimentin were evaluated on FFPE blocks using Ventana Benchmark XT Autoimmunostainer (Ventana, USA). The commercially available antibodies used were anti-CD56 (clone 123C3, Dako), anti-E-cadherin (clone NCS38, Dako) and anti-Vimentin (cloneV9, Biogenex).3-4 $\mu \mathrm{m}$ thin sections were cut on microtome (Leica, Germany) and taken on to 3-Aminopropyltriethoxysilane (APES) coated slides. Briefly, the protocol includes following steps of deparaffinization using EZ solution, Antigen retrieval for 60 minutes using retrieval solution $\mathrm{CC} 1$, and incubation with ultraview DAB Inhibitor for 4 minutes, Addition of 100 $\mu 1$ of anti-E-cadherin, anti-Vimentin antibody at $370^{\circ} \mathrm{C}$ for 32 minutes, anti-CD56 antibody at $370^{\circ} \mathrm{C}$ for 48 minutes respectively. Followed by Ultra-view HRP Multimer for 8 minutes, counterstained with Hematoxylin for 8 minutes and mounted with DPX. For NK cells, the numbers of tumor infiltrating NK cells were counted in three different fields and mean value for each filed was calculated and based on the its median value patients were grouped into Low expression group and High expression group. For Ecadherin and Vimentin expression, scoring was done on the basis of intensity and percentage of cell population $(\%)$ in to Negative $(<10 \%$ cells), and positive $(>10 \%$ cells). They were further grouped in to grade I (10-30\%), II (30-50\% and III (>50\%).

Statistical analysis was carried out using SPSS statistical software version 20 (SPSS Inc, USA).

\section{Results}

In comparison with Healthy Controls, OSCC patients had a significant increased Mean \pm SD value of WBC and a trend of decreased Mean \pm SD value of Lymphocytes. While an incidence of higher Mean \pm SD values were obtained for NK cells populations. NK cells were further categorised into $\mathrm{CD}^{\mathrm{dim}}$ and CD56 ${ }^{\text {bright }}$ population (Table 1 ).

Table 1: WBC and NK cells comparison in blood of OSCC patients with healthy controls

\begin{tabular}{|c|c|c|c|}
\hline & $\begin{array}{l}\text { Healthy controls } \\
\qquad(\mathrm{N}=10)\end{array}$ & $\begin{array}{l}\text { OSCC } \\
(\mathrm{N}=30)\end{array}$ & P Value \\
\hline WBC & $59.8 \times 10^{3} \pm 10.8$ & $89.5 \times 10^{3} \pm 28.1$ & $0.002 *$ \\
\hline Lymphocytes & $27.5 \pm 3.60$ & $23.5 \pm 6.20$ & 0.061 \\
\hline ALC & $1.6 \pm 0.36$ & $2.0 \pm 0.75$ & 1.07 \\
\hline NK CD56 $^{\text {Dim }}$ & $8.1 \pm 2.70$ & $10.0 \pm 1.8$ & 0.461 \\
\hline NK CD56 ${ }^{\text {Bright }}$ & $0.8 \pm 2.70$ & $1.0 \pm 0.08$ & 0.660 \\
\hline
\end{tabular}
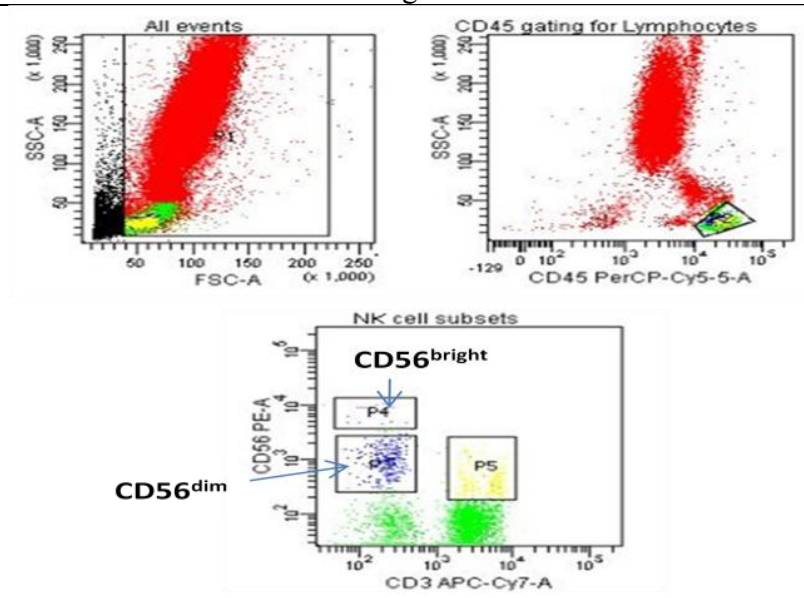

Figure: 1 Representative dot plot showing NK cells population of Oral cancer patients 


\section{JMSCR Vol||06||Issue||07||Page 974-980||July}

Based on Immunohistochemistry analysis of OSCC patients $(\mathrm{N}=30)$, Tumor infiltrating $\mathrm{NK}$ cells expression was found lower in 60\% (18/30) and higher in $40 \%(12 / 30)$ patients. E-cadherin expression was found to be lower in $40 \%(12 / 30)$ and higher in $60 \%(22 / 30)$ of patients. While Vimentin expression was found to be lower in $73 \%$ majority of patients (22/30) and Higher in 24\% (8/30). It was further correlated with the clinicopathological parameters such as age, gender, habit, tumor site, tumor size, disease stage, histological grade, lymphatic permeation and Perineural invasion.

In accordance with clinicopathological characteristics, a higher incidence of Tumor infiltrating NK cells was observed in patients with perineural invasion $(80 \%$, (4/5). In case of EMT markers, a significant higher E-cadherin expression was observed in patients who were habituated to tobacco $(71 \%, \mathrm{p}=0.050)$ and asignificant increase of Vimentin expression $(40 \%, p$ value $=0.020)$ is observed with highly invasive type of tumor. Characteristic trend of higher Vimentin expression was observed in patients who had poorly differentiated Grade III tumors (100\%, 4/4, p value $=0.060)$ (Table 2 , supplementary document $)$.

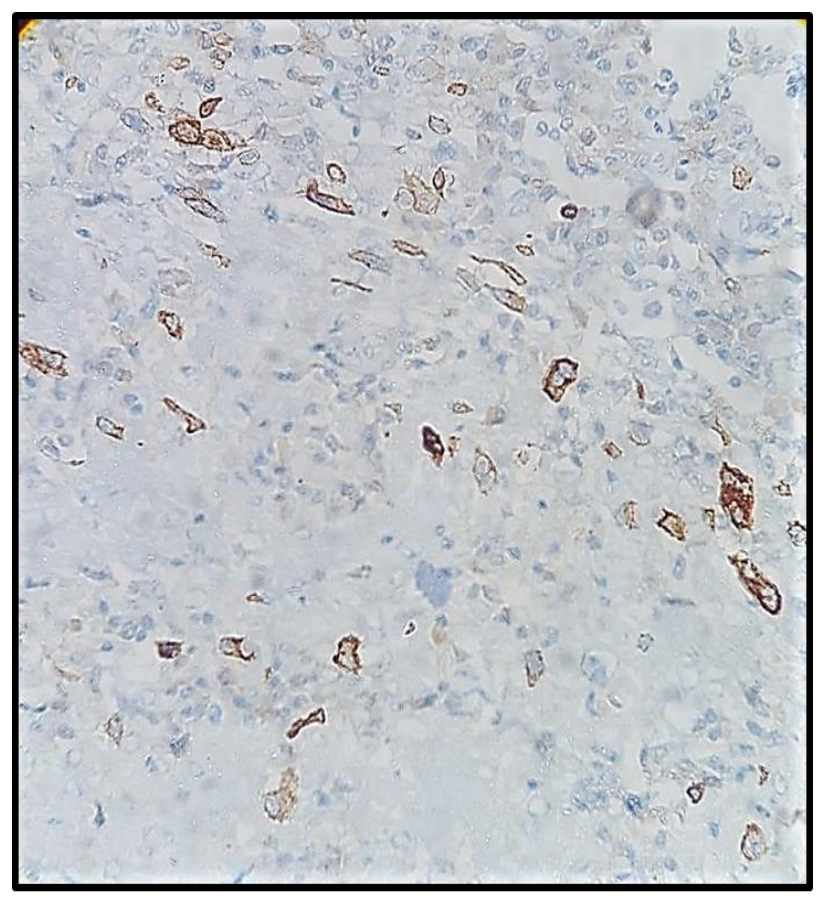

Figure 2 Membranous expression of Tumor infiltrating NK cells

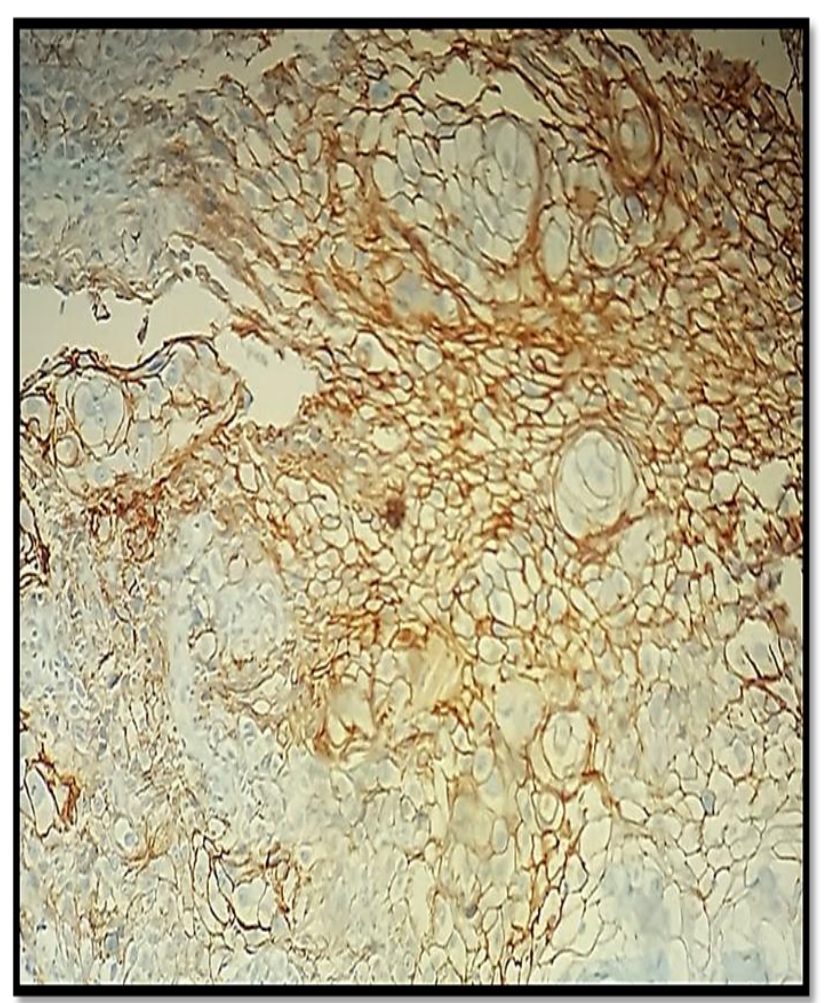

Figure: 3 Membranous expression of E-cadherin

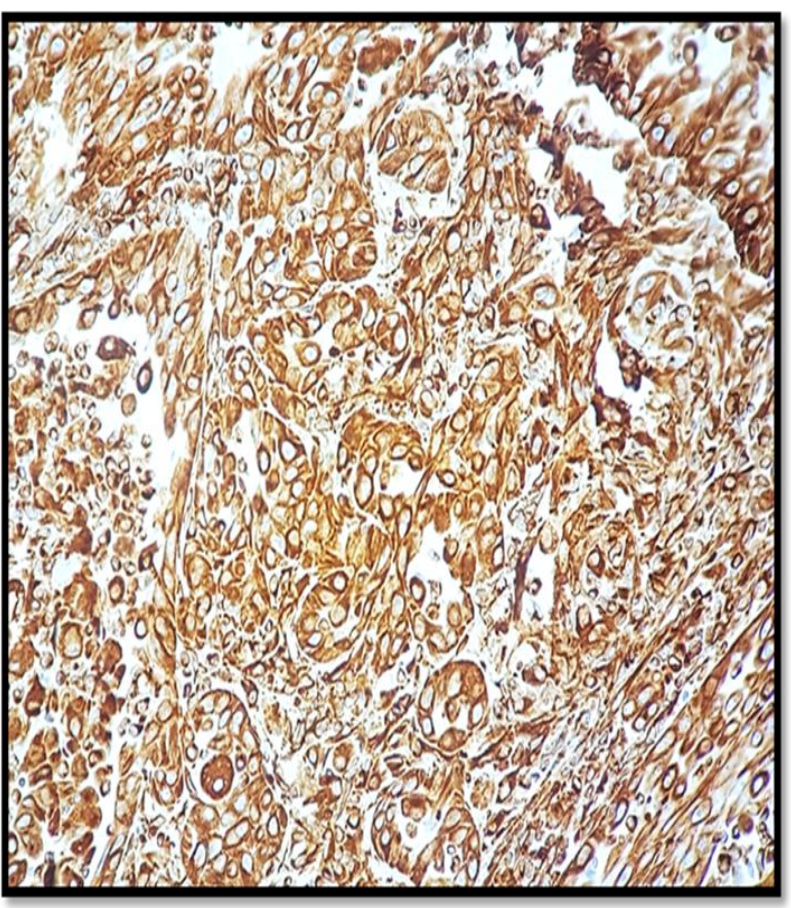

Figure: 4 Cytoplasmic expression of Vimentin 
Table:2 Correlation of Tumor infiltrating NK cells and EMT markers with Clinicopathological parameters

\begin{tabular}{|c|c|c|c|c|c|c|c|c|c|c|}
\hline \multicolumn{2}{|l|}{ Characteristics } & \multirow{3}{*}{$\begin{array}{l}\mathrm{N} \\
14\end{array}$} & \multicolumn{2}{|c|}{$\begin{array}{c}\text { Tumor infiltrating NK } \\
\text { cells }\end{array}$} & \multirow{3}{*}{$\begin{array}{l}\mathrm{N} \\
14\end{array}$} & \multicolumn{2}{|c|}{ E-cadherin } & \multirow{3}{*}{$\begin{array}{l}\mathrm{N} \\
14\end{array}$} & \multicolumn{2}{|c|}{ Vimentin } \\
\hline & & & Negative & Positive & & Negative & Positive & & Negative & Positive \\
\hline \multirow{2}{*}{ Age } & $<45$ & & $9(64 \%)$ & $5(36 \%)$ & & $6(43 \%)$ & $8(57 \%)$ & & $12(86 \%)$ & $2(14 \%)$ \\
\hline & $\geq 45$ & 16 & $9(56 \%)$ & $7(44 \%)$ & 16 & $6(38 \%)$ & $10(62 \%)$ & 16 & $10(63 \%)$ & $6(37 \%)$ \\
\hline \multirow{2}{*}{ Habit } & $\begin{array}{c}\text { Without } \\
\text { Habit }\end{array}$ & 9 & $5(56 \%)$ & $4(44 \%)$ & 9 & $6(67 \%)$ & $3(33 \%)$ & 9 & $6(67 \%)$ & $3(33 \%)$ \\
\hline & $\begin{array}{l}\text { Without } \\
\text { Habit }\end{array}$ & 21 & $13(62 \%)$ & $8(38 \%)$ & 21 & $6(29 \%)$ & $15(71 \%)$ & 21 & $16(76 \%)$ & $5(24 \%)$ \\
\hline \multirow{3}{*}{ Tumor Size } & $\mathrm{T} 1$ & 13 & $8(62 \%)$ & $5(38 \%)$ & 13 & $6(67 \%)$ & $7(54 \%)$ & 13 & $10(77 \%)$ & $3(23 \%)$ \\
\hline & $\mathrm{T} 2$ & 11 & $8(73 \%)$ & $3(27 \%)$ & 11 & $2(18 \%)$ & $9(82 \%)$ & 11 & $8(73 \%)$ & $3(27 \%)$ \\
\hline & $\mathrm{T} 4$ & 6 & $2(33 \%)$ & $4(67 \%)$ & 6 & $4(67 \%)$ & $2(33 \%)$ & 6 & $4(67 \%)$ & $2(33 \%)$ \\
\hline \multirow{4}{*}{ Nodal Status } & N0 & 21 & $11(52 \%)$ & $10(48 \%)$ & 21 & $8(38 \%)$ & $13(62 \%)$ & 21 & $15(71 \%)$ & $6(29 \%)$ \\
\hline & $\mathrm{N} 1$ & 5 & $5(100 \%)$ & $0(0 \%)$ & 5 & $1(20 \%)$ & $4(80 \%)$ & 5 & $4(80 \%)$ & $1(20 \%)$ \\
\hline & $\mathrm{N} 2$ & 3 & $1(33 \%)$ & $2(67 \%)$ & 3 & $3(100 \%)$ & $0(00 \%)$ & 3 & $2(67 \%)$ & $1(33 \%)$ \\
\hline & N3 & 1 & $1(100 \%)$ & $0(0 \%)$ & 1 & $0(0 \%)$ & $1(100 \%)$ & 1 & $1(100 \%)$ & $0(0 \%)$ \\
\hline \multirow{3}{*}{ Stage } & Stage I & 12 & $7(58 \%)$ & $5(42 \%)$ & 12 & $6(50 \%)$ & $6(50 \%)$ & 12 & $9(75 \%)$ & $3(25 \%)$ \\
\hline & Stage II & 11 & $8(73 \%)$ & $3(27 \%)$ & 11 & $2(19 \%)$ & $9(81 \%)$ & 11 & $8(73 \%)$ & $3(27 \%)$ \\
\hline & Stage IV & 7 & $3(43 \%)$ & $4(57 \%)$ & 7 & $4(57 \%)$ & $3(43 \%)$ & 7 & $5(71 \%)$ & $2(29 \%)$ \\
\hline \multirow{3}{*}{$\begin{array}{l}\text { Histological } \\
\text { Grade }\end{array}$} & G1 & 13 & $8(62 \%)$ & $5(38 \%)$ & 13 & $4(30 \%)$ & $9(70 \%)$ & 13 & $4(30 \%)$ & $9(70 \%)$ \\
\hline & G2 & 13 & $6(46 \%)$ & $7(54 \%)$ & 13 & $8(62 \%)$ & $5(38 \%)$ & 13 & $8(62 \%)$ & $5(38 \%)$ \\
\hline & G3 & 4 & $4(100 \%)$ & $0(0 \%)$ & 4 & $0(0 \%)$ & $4(100 \%)$ & 4 & $0(0 \%)$ & $4(100 \%)$ \\
\hline \multirow{2}{*}{$\begin{array}{l}\text { Lymphatic } \\
\text { Permeation }\end{array}$} & Absent & 26 & $14(54 \%)$ & $12(46 \%)$ & 26 & $12(46 \%)$ & $14(54 \%)$ & 26 & $19(73 \%)$ & $7(27 \%)$ \\
\hline & Present & 4 & $4(100 \%)$ & $0(0 \%)$ & 4 & $0(0 \%)$ & $4(100 \%)$ & 4 & $3(75 \%)$ & $1(25 \%)$ \\
\hline \multirow{2}{*}{$\begin{array}{l}\text { Perineural } \\
\text { Invasion }\end{array}$} & Absent & 25 & $17(68 \%)$ & $8(32 \%)$ & 25 & $10(40 \%)$ & $15(60 \%)$ & 25 & $18(72 \%)$ & $7(28 \%)$ \\
\hline & Present & 5 & $1(20 \%)$ & $4(80 \%)$ & 5 & $6(43 \%)$ & $8(57 \%)$ & 14 & $12(86 \%)$ & $2(14 \%)$ \\
\hline
\end{tabular}

Further, we correlated, circulating NK cells with NK cells infiltrated at tumor front and EMT markers along with disease stage, a significant positive correlation of circulating CD56 ${ }^{\text {Dim }} \mathrm{NK}$ cells was observed with tumor infiltrating NK cells $(\mathrm{P}=0.02)$ and a negative correlation was observed with Ecadherin though a value was not statistically significant. With disease stage, a positive correlation of $\mathrm{CD}_{5} 6^{\mathrm{Dim}}$ and negative correlation $\mathrm{CD} 6^{\text {Bright }}$ was observed $(\mathrm{P}=0.05)$ (Table 3$)$.
Table 3: Correlation of Circulating NK cells with tumor infiltrating NK cells and EMT markers

\begin{tabular}{|c|c|c|}
\hline Marker & $\begin{array}{c}\text { Circulating } \\
\text { CD56 }^{\text {Dim }}\end{array}$ & $\begin{array}{l}\text { Circulating } \\
\text { CD56 }^{\text {Bright }} \\
\end{array}$ \\
\hline \multicolumn{3}{|c|}{ Spearman's correlation $\left(* \mathrm{R}_{\mathrm{S}}\right.$ Correlation coefficient $)$} \\
\hline $\begin{array}{l}\text { Tumor } \\
\text { infiltrating } \mathrm{NK} \\
\text { cells }\end{array}$ & $0.422 *$ & -0.188 \\
\hline E-Cadherin & -0.281 & -0.035 \\
\hline Vimentin & 0.14 & -0.15 \\
\hline Disease Stage & $0.340 *$ & $-0.035^{*}$ \\
\hline
\end{tabular}

Moreover, a high incidence of Tumor infiltrating NK cells expression was associated with lower Ecadherin expression (59\%, p value $=0.094)$ and a higher Vimentin expression $(50 \%, \mathrm{p}$ value $=0.018)$ (Table 4 Supplementary material). 


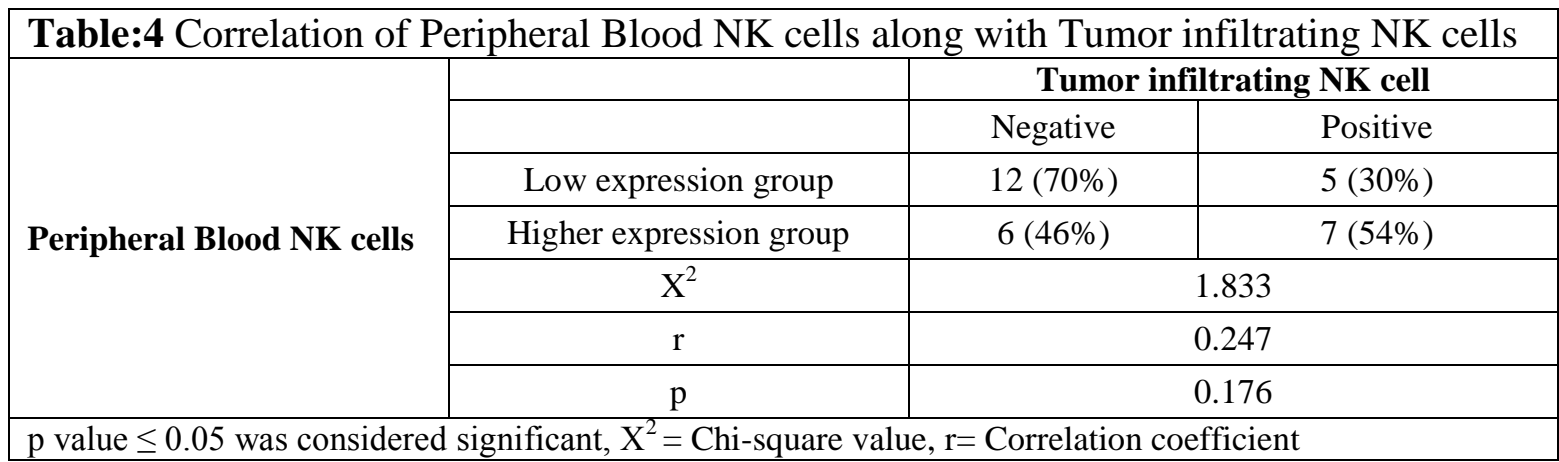

\section{Discussion}

It is conceived that NK cells mount response against haematological malignancies which are more easily accessible through circulation, in contrast to solid tumours, as NK cells and Cytotoxic $\mathrm{T}$ cells are functionally exhausted due to cancer "immunoediting" that is mainly observed during $\mathrm{EMT}^{(11)}$. It has to be considered that peripheral blood NK cells might display many differences with regards to phenotype and function compared to infiltration of NK cells in the tumor tissue. Only few studies address the issue of the potential changes in tumor immunogenicity during EMT mediated by immune cells like NK cells and $\mathrm{T}$ cells via the induction of altered cell-cell signalling changes of TGF $\beta$, FGFR receptors or E-cadherin loss ${ }^{(12)}$.

In present study, we have tried to understand NK cell changes during EMT process in OSCC. In our study, a significant increased WBC with decreased Lymphocytes count in peripheral blood circulation of patients suggests a systemic inflammatory response, which can be associated with alterations in circulating WBC's which due to increase in number of circulating Neutrophils ordue to the presence of Lymphopenia as suggested by Gabay et al. (1999) ${ }^{(13)}$ and Zahorec et al. (2001) ${ }^{(14)}$.

Our study shows a higher incidence of NK cells expression both in circulation and at tumor front which is in resemblance to the findings suggested by Céspede et al. (2011) in cervical cancer ${ }^{(15)}$, suggests a feed forward infiltration of NK cells from circulation to tumor microenvironment.

Analysis done by Vural et al. in $2000{ }^{(16)}$ suggests that in filtration of NK cells in perineural spaces of up to $52 \%$ of OSCC cases marks as a predictor for metastasis and loco regional recurrence. Similar to this result, in present study, higher Tumor infiltrating NK cells was observed with the presence of Perineural invasion.

NK cells mainly have two functions, one is of having cytotoxic activity against tumor antigens and other is the secretion of IFN- $\gamma$. CD56 ${ }^{\text {Dim }}$ subsets are highly cytotoxic and produce less IFN- $\gamma$, while $\mathrm{CD} 6^{\text {bright }}$ have opposite characteristic ${ }^{(17)}$. A positive correlation of $\mathrm{CD} 56^{\text {Dim }}$ with tumor infiltrating NK cells in our study shows migration of cytotoxic NK cells at tumor front which is mainly occurs through chemo attractants present at tumor site. However, in relation to disease status, inverse correlation suggest that NK cells initially have control on tumor but in advance stage it supports tumor for invasion.

Subsequently, the inter marker-correlation not only acknowledges a trend of decreased expression of Ecadherin but also a significant increase of Vimentin expression in accordance with Tumor infiltrating NK cells expression promoting a pro-invasive EMT phenotypein oral cancer which hasn't been reported earlier as per the best knowledge.

Although the role of NK cells in the control of primary tumors remains debatable, our current study highlights that Tumor infiltrating NK cells might have a role in development of EMT and this might be due to its dynamic association with focal adhesion molecules ${ }^{(18)}$.

This is a preliminary study performed on smaller sample size to ascertain the dynamics of NK cells in correlation with EMT markers. One possible limitation of this study is the shorter follow-up period. Nevertheless, in future we would like to undertake more patients and continue with cytokine study and patient's diseased status. 


\section{Conclusion}

The present investigation features the influence of NK cells on EMT by mediating an aberrant loss of E-cadherin and an upregulation of Vimentin, thereby inducing transient properties for tumor cells which promptapro-invasive tumor phenotype. Early changes associated with EMT are hard to envision morphologically in tumor sections therefore early detection of EMT may anticipate likely invasive behaviour and could aid in advancement of enhanced anticancer immunotherapeutic strategies in the coming years.

\section{Acknowledgments}

This study was supported by The Gujarat Cancer and Research Institute, Ahmadabad, Gujarat and is approved by the Institutional Scientific Review Board and Ethics Committee. Patients provided the informed consent to use their sample for this study.

\section{Conflicts of Interests}

All authors confirm that there are no conflicts of interest associated with this publication.

\section{References}

1. Cooper, M. A., Fehniger, T. A., Turner, S. C., Chen, K. S., Ghaheri, B. A., Ghayur, T. Caligiuri, M. A. (2013). Human natural killer cells: a unique innate immunoregulatory role for the CD56 bright subset Library, 97(10), 3146-3151.

2. Imai K, Matsuyama S, Miyake S, Suga K, Nakachi K. Natural cytotoxic activity of peripheral-blood lymphocytes and cancer incidence: an 11-year follow-up study of a general population. Lancet. 2000;356 (9244):1795-1799.

3. Stojanovic, A. and Cerwenka, A. (2011). Natural killer cells and solid tumors. Journal of Innate Immunity,3(4),355-364. https://doi.org/10.1159/000325465

4. Kalluri, R., \& Weinberg, R. a. (2009). Review series the basics of epithelialmesenchymal transition. Journal of Clinical Investigation, 119(6), 1420-1428.
5. Huber MA, Kraut N, Beug H. Molecular requirements for epithelial-mesenchymal transition during tumor progression. Curr Opin Cell Biol2005; 17:548-558

6. Mandal M, Myers JN, Lippman SM, et al. Epithelial to mesenchymal transition in head and neck squamous carcinoma: association of Src activation with E-cadherin downregulation, vimentin expression, and aggressive tumor features. Cancer 2008; 112:2088-2100

7. Liu, L. K., Jiang, X. Y., Zhou, X. X., Wang, D. M., Song, X. L., \& Jiang, H. B. (2010). Upregulation of vimentin and aberrant expression of E-cadherin/B-catenin complex in oral squamous cell carcinomas: Correlation with the clinicopathological features and patient outcome. Modern Pathology.

8. Liu, P. F., Kang, B. H., Wu, Y. M., Sun, J. H., Yen, L. M., Fu, T. Y.\& Hsieh, I. C. (2017). Vimentin is a potential prognostic factor for tongue squamous cell carcinoma among five epithelial-mesenchymal transition-related proteins. PloS one, 12(6), e0178581.

9. Lamouille S, Xu J, Derynck R. Molecular mechanisms of epithelial-mesenchymal transition. Nat Rev Mol Cell Biol. 2014;15(3):178-196.

10. Lehembre, F., Yilmaz, M., Wicki, A., Schomber, T., Strittmatter, K., Ziegler, D., Christofori, G. (2008). NCAM-induced focal adhesion assembly: A functional switch upon loss of E-cadherin. EMBO Journal (2008) 27, 2603-261.

11. Schreiber, R. D., Old, L. J., \& Smyth, M. J. (2011). Cancer immunoediting: integrating immunity's roles in cancer suppression and promotion. Science, 331(6024), 1565-1570.

12. Frame, M. C., \& Inman, G. J. (2008). NCAM Is at the Heart of Reciprocal Regulation of E-Cadherin- and Integrin-Mediated Adhesions via Signalling Modulation. Developmental Cell, 15(4), 494-496. 
13. Gabay, C., \& Kushner, I. (1999). Acutephase proteins and other systemic responses to inflammation. New England journal of medicine, 340(6), 448-454.

14. Zahorec, R. (2001). Ratio of neutrophil to lymphocyte counts-rapid and simple parameter of systemic inflammation and stress in critically ill. Bratislavske lekarske listy, 102(1), 5-14.

15. Cespedes, M. A., Rodríguez, J. A., Medina, M., Bravo, M., \&Cómbita, A. L. (2012). Analysis of NK cells in peripheral blood and tumor infiltrating lymphocytes in cervical cancer patients. RevistaColombiana de Cancerología, 16(1), 16-26.

16. Vural E, Hutcheson J, Korourian S, Kechelava S, Hanna E. Correlation of neural cell adhesion molecule with perineural spread of squamous cell carcinoma of head and neck. Otolaryngol Head Neck Surg 2000; 122:717-20.

17. Cantoni, C., Huergo-Zapico, L., Parodi, M., Pedrazzi, M., Mingari, M. C., Moretta, A., ... \& Castriconi, R. (2016). NK cells, tumor cell transition, and tumor progression in solid malignancies: new hints for NK-based immunotherapy. Journal of immunology research, 2016.

18. Frame, M. C., \& Inman, G. J. (2008). NCAM Is at the Heart of Reciprocal Regulation of E-Cadherin- and Integrin-Mediated Adhesions via Signalling Modulation. Developmental Cell, 15(4), 494-496. 